\title{
Are Females More Sensitive to MDMA-Related Discriminative Stimuli?
}

\author{
J.H. Broadbear ${ }^{*}$, B. Tunstall and K. Beringer
}

School of Psychology and Psychiatry, Monash University, Clayton, Australia

Keywords: MDMA, drug discrimination, rat, sex difference, amphetamine, carbetocin

\section{INTRODUCTION}

MDMA is a stimulant-derived drug of abuse that has mood altering effects [1]. MDMA-induced changes in affect

\section{METHODS}

Male and female Sprague Dawley rats $(\mathrm{M}=12, \mathrm{~F}=12)$ were trained to reliably differentiate between MDMA $(1.5 \mathrm{mg} / \mathrm{kg})$ and
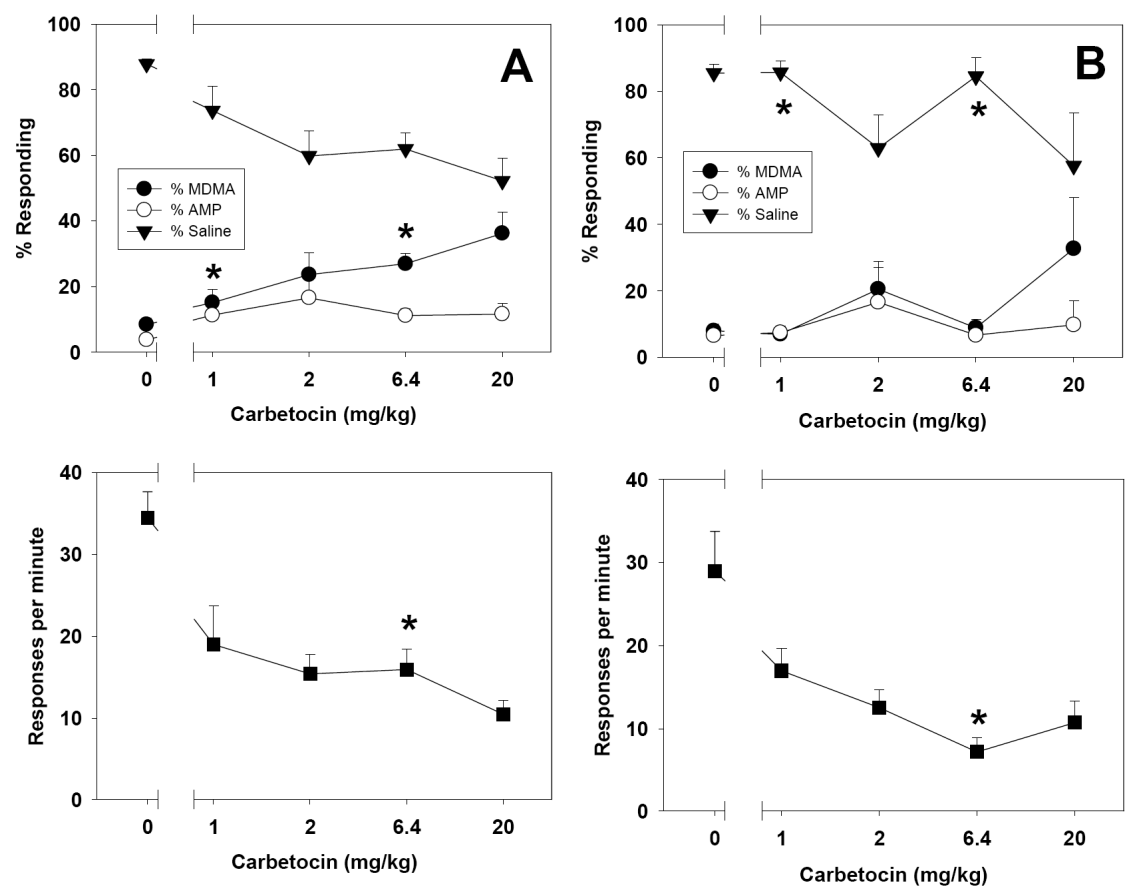

Fig. (1). Distribution of responses across levers and rates of responding following carbetocin treatment in female (Panel A) and male (Panel B) rats trained to discriminate between MDMA, AMP and SAL (n=6-11).

* Statistical difference between male and female behavioral responses.

are examples of interoceptive cues which enable experienced users to distinguish the effects of MDMA from those of other drugs. Serotonin neurotransmission positively modulates the release of oxytocin into plasma [2]. To test the hypothesis that oxytocin receptor activation contributes to the interoceptive cues of MDMA in male and female rats, two peptidic oxytocin receptor ligands, the agonist carbetocin [3] and antagonist atosiban [4], were utilised in a 3-way drug discrimination paradigm [5].

*Address correspondence to this author at the School of Psychology and Psychiatry, Monash University, Clayton, Australia;

Tel: +613 9905 3903; Fax: +613 9905 3948;

E-mail: Jillian.Broadbear@monash.edu a related stimulant, dl-amphetamine (AMP; $1.0 \mathrm{mg} / \mathrm{kg})$ ), and saline (SAL) using a three lever drug discrimination paradigm. The extent to which substitution with carbetocin (oxytocin analogue) or co-administration with atosiban (oxytocin receptor antagonist) affected drug-appropriate responding was evaluated with sex as a covariate. The outcome measures of interest were proportion of responding on each of the training drug-associated levers, as well as rate of lever pressing (responses/min).

\section{RESULTS}

Substitution with an oxytocin analogue (carbetocin) partially generalised to the MDMA-training cue, whereas blocking oxytocin receptors with atosiban resulted in a selective disruption of MDMA- but not AMP-appropriate responding. Female rats appeared to be more sensitive to 
MDMA-like cues based on their greater propensity to respond on the MDMA lever following a low dose of MDMA, low doses of AMP and carbetocin substitution (for example, see Fig. 1).

In addition, female rats appeared to be less sensitive to the rate-suppressing effects of a range of drug treatments, including MDMA, AMP, carbetocin and atosiban.

\section{DISCUSSION}

Oxytocin is released subsequent to MDMA administration in humans and animals $[6,7]$. The results of this study suggest that there may be an important role for oxytocin in the subjective changes in perception that are experienced following MDMA treatment. However, the partial generalisation to the MDMA training cue produced by substitution with carbetocin suggests that oxytocin receptor activation alone cannot explain all interoceptive changes that arise following MDMA use. The evidence for sex differences in the perceived effects of MDMA as well as drugs that may have MDMA-like interoceptive cues is consistent with earlier observations that women/females are more sensitive to the psychological effects of MDMA; conversely, the relative sensitivity of male rats to the ratesuppressing effects is supported by studies that have found $\mathrm{men} / \mathrm{males}$ to be more sensitive to physical drug effects (see review in [8]).

\section{CONCLUSIONS}

The findings from the present study highlight the similarities between the interoceptive effects of oxytocin and of MDMA, suggesting that oxytocin contributes to affective changes subsequent to MDMA exposure. The greater sensitivity of females to MDMA-associated cues, and of males to the rate-suppressing effects of drug treatments, provide further evidence of the importance of gender in the perception of drug effects.

\section{REFERENCES}

[1] Johanson CE, Kilbey M, Gatchalian K, Tancer M. Discriminative stimulus effects of 3, 4-methylenedioxymethamphetamine (MDMA) in humans trained to discriminate among damphetamine, meta-chlorophenylpiperazine and placebo. Drug Alcohol Dep 2006; 81: 27-36.

[2] Jørgensen H, Kjaer A, Knigge U, Möller M, Warberg J. Serotonin stimulates hypothalamic mRNA expression and local release of neurohypophysial peptides. J Neuroendocrinol 2003; 15: 564-71.

[3] Gimpl G, Postina R, Fahrenholz F, Reinheimer T. Binding domains of the oxytocin receptor for the selective oxytocin receptor antagonist barusiban in comparison to the agonists oxytocin and carbetocin. Eur J Pharmacol 2005; 510: 9-16.

[4] Manning M, Miteva K, Pancheva S, Stoev S, Wo NC, Chan WY Design and synthesis of highly selective in vitro and in vivo uterine receptor antagonists of oxytocin: comparisons with Atosiban. Int J Pept Protien Res 1995; 46: 244-52.

[5] Goodwin AK, Baker LE. A three-choice discrimination procedure dissociates the discriminative stimulus effects of d-amphetamine and (+-)-MDMA in rats. Exp Clin Psychopharmacol 2000; 8: 41523.

[6] Wolff K, Tsapakis EM, Winstock AR, et al. Vasopressin and oxytocin secretion in response to the consumption of ecstasy in a clubbing population. J Psychopharmacol 2006; 20: 400-10.

[7] Thompson MR, Callaghan PD, Hunt GE, Cornish JL, McGregor IS. A role for oxytocin and 5-HT 1A receptors in the prosocial effects of 3, 4 methylenedioxymethamphetamine. Neuroscience 2007; 146: 509-14.

[8] Allott K and Redman J. Is there sex differences associated with the effects of ecstasy/3, 4-methylenedioxymethamphetamine (MDMA)? Neurosci Biobehav Rev 2007; 31: 327-47. 